\title{
De seres humanos reais e performers verdadeiros ${ }^{1}$ \\ Annemarie M. Matzke \\ Trad. Stephan Baumgärtel²
}

\section{Resumo}

Este artigo discute noções como autenticidade e veracidade no trabalho cênico frente ao crescente interesse em usar depoimentos biográficos de atuantes não-profissionais. $\mathrm{O}$ artigo se questiona sobre as fontes desse interesse bem como as diferenças dessas práticas teatrais em relação a formatos televisivos que trabalham com depoimentos biográficos e reflete sobre diferentes efeitos de autenticidade que se pode produzir com um teatro documentário que oscila entre ficção e realidade empírica.

PALAVRAS-CHAVE: teatro documentário - teatro pós-dramático - prática de atuação teatral - teatralidade

\section{Abstract}

Leo Sykes speaks about her training and her work as a theatre director. She tells of her five years as assistant director to Eugenio Barba, director of Odin Teatret. She explains how she works to make clown performances with Circo Teatro Udi Grudi in Brazil and with Teatret OM in Denmark. She shows how she works with the actors to develop the material and then elaborates and structures it into a performance.

KEYWORDS: Leo Sykes, Eugenio Barba, Clown

\footnotetext{
1 In: Fischer-Lichte, Erika et. al. (eds.). Wege der Wahrnehmung. Authentizität, Reflexivität und Aufmerksamkeit im zeitgenössischen Theater. Berlin: Theater der Zeit, 2006. pp. 39 - 47. Trad. Stephan Baumgärtel, Prof. do PPGT da UDESC
} 
U ma mulher entra no palco. Na As apresentações são organizados segundo mão, ela carrega uma lâmpada um regulamento reconhecível. A pesar de pé, um modelo de IKEA dessa delimitação formal da encenação, Ela procura um lugar, põe a cria-se um impacto especial de vivencia lâmpada no chão e começa imediata. Tudo parece 'real', como se a a contar: do salário de desemprego, da 'atuadora' o trouxesse diretamente da sua redução da assistência social do governo vida cotidiana para o palco. No caso da e as injustiças; da necessidade de cada lâmpada de pé, trata-se de uma lâmpada de um se engajar e do fato que ela está farta; IKEA que pode ser encontrada em muitos como é preciso que se faça algo, cada um lares, e a roupa tampouco é reconhecível, de nos. Durante a fala, ela perde a fluência, de modo específico, como figurino. A chega a parar momentaneamente. Cria-se forma da apresentação também subverte a impressão como ela estivesse fala o seu certas convenções de uma apresentação texto de modo livre, como se ela decidisse teatral. Durante a sua fala, a 'atriz' é espontaneamente o que dizer. Ouve- nervosa, comete erros de pronuncia, mas se o tictac de um relógio. A luz se apaga exatamente por causa deste modo faltoso lentamente - um minuto se passou: um de falar o seu discurso aparenta ser nãominuto na luz do palco.

Essa cena curta provém da encenação Tableau com existências marginais (Standbild mit Randexistenzen) de Björn Auftrag eStefanie Lorey de 2004. ${ }^{3}$ O conceito da encenação é buscar, via anúncios nos jornais, pessoas que gostariam dizer algo no palco, é colocar a sua disposição um minuto de tempo cênico. Este minuto pode ser usado de modo arbitrário. $\mathrm{O}$ pressuposto é que cada um traz consigo a sua própria lâmpada de pé. Aos poucos configura-se no palco uma 'imagem de grupo' composta pelos trinta e cinco 'atores': alguém conta uma piada sobre Bush, uma outra pessoa conta do seu cunhado que morreu de câncer uma fica em silêncio por um minuto. Do lado-a-lado dos diferentes discursos surge um caleidoscópio de confissões, histórias, anedotas pessoais, ou discursos engajados, que realça a individualidade dos diferentes representadores (de si mesmo). A previsão de Andy Warhol que no futuro cada um de nos poderia ganhar fama por quinze minutos, é realizado aqui no palco pelo menos por um minuto.

A organização da encenação é simples e transparente para o espectador. $\mathrm{O}$ palco a luz da lâmpada de pé e o limite de tempo atribuem a cada apresentação uma moldura.

Apresentaçōes, entre outras, no Mousonturm em Frankfur Main, no teatro Hebbel am Ufer em Berlin, no Disk
Gießen, e no teatro Die Kammerspiele em München. encenado. Será que tudo que se opõe à

construção do acontecimento teatral,

por tanto ao seu caráter encenado, produz um efeito de autenticidade? Com isso, autenticidade no palco seria aquilo que parece ser não-encenado, mesmo que encenação organiza um visível contexto de encenação.

Talvez a impressão de autenticidade seja produzida por uma especia confiabilidade da 'atuadora' que convence a mim, a espectadora, que ela realmente quer dizer o que ela fala. À diferença de um ator que fala em nome de um personagem, ele formula um assunto pessoal. Ela responde por aquilo que diz. Pode-se imaginar que repetiria as suas reivindicações na rua durante uma manifestação: autenticidade como uma forma de street credibility. Será que a impressão de imediatez se cria exatamente pela contradição entre a proximidade cotidiana da 'atriz' e a delimitação exposta da encenação?

A formulação do 'ser humano real' com que intitulei o meu ensaio é propositalmente polêmica: no palco e no

dia-a-dia, todo ser humano é naturalmente 'real', independentemente sé é um ator ou uma funcionária de um banco. Mas perante a crescente prática no teatro contemporâneo de colocar atores não-profissionais no palco, parece necessário realizar algumas diferenciações. Da onde vem o interesse na encenação de atores não-profissionais? Onde encontra-se a diferença em relação a formatos da mídia como o Talkshow ou os Reality Soaps? Quais efeitos de autenticidade são produzidos, quando se aposta não em atores profissionais, mas na apresentação de pessoas comuns?

Comparando as encenações que surgem neste contexto, chama a atenção que os 'atuadores' apresentam a sua história, a sua situação empírica, e por tanto, apresentam eles mesmos. Na maioria das vezes, eles não representam mais personagens literários ou figuras dramáticas - e caso que o fazem, é para refletir sobre a própria situação de vida. ${ }^{4}$ Eles são postos em cena como expertos da própria causa: como 'especialistas do cotidiano'. ${ }^{5}$ Eles se apresentam a si mesmos ou um assunto pessoal, como na encenação descrita no início. É um teatro biográfico com uma abordagem documentária.

No entanto, essa definição é pertinente também para muitas apresentações no âmbito do teatro-performance. Elas também mostram, a partir de questionamentos pessoais, encenações de um Eu além da representação de uma figura. Nenhum texto literário é ponto de partida para a montagem, mas os 'atores' tornam a si mesmo, sua biografia ou corporeidade, o assunto da apresentação. O que se mostra não é um teatro auto-biográfico. Estas encenações do Eu são discussões de formas de encenação sociais e midiáticas, que são reconhecíveis nos trabalhos. Como exemplos, pode-se mencionar o Quizshow da produção QUIZOOLA! do grupo Forced Entertainment, o Setting Ballsaal na encenação WARUM TANZT IHR NICHT? [Porque vocês não estão dançando?] do grupo SheShePop, ou o mundo do trabalho como lugar de um auto-marketing na performance WORK do grupo Gob Squad.

${ }^{4} \mathrm{Na}$ encenação Wallenstein (2005), do grupo Rimini-Protoko

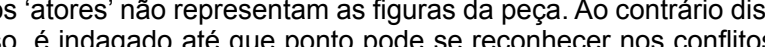
na biografia dos 'atores' os conflitos do drama. Behrend, Eva. "Die Alltagsspezialisten", in Jahrbuch Theater heute (2003), p.52-63. Exemplos para esta forma de teatro săo Lindholm, para mencionar só alguns.
As encenações revelam indagações nos modos sociais de encenação. São citados formatos da mídia ou cultural performances, que precisam uma forma especifica da auto-apresentação.

Este procedimento se mostra também nas encenações de atores não-profissionais, que muitas vezes, sem qualquer tipo de formação de ator, são profissionais na autopresentação. Ao por, na sua encenação de Wallenstein, na pessoa deSven-Joachim Otto um político profissional no palco, o grupo Rimini-Protokoll não só tematiza modos de uto-apresentação profissionais - durante encenação, Otto revela, por exemplo, as estratégias da sua campanha publicitária mas os expõe no próprio ato de apresentar e jogar cenicamente. Uma discussão parecida com a auto-promoção mostra a rilogia PeRform PeRForming do bailarina performer Jochen Roller, que indaga no seu trabalho "o sentido e o absurdo de compreender a dança como trabalho". Agui, o negocio com a auto-revelação se ransforma no show propriamente dito. Portanto, as transições entre o performer que torna a própria pessoa assunto da sua apresentação, e o 'ator' não-profissional que recorre a suas estratégias pessoais de representar o próprio $E u$, não são claramente delimitadas. Ambos fazem da sua competência na auto-encenação o tema da sua apresentação e com isso aludem um fenômeno social: a necessidade de aber como se auto-promover, e portanto obrigação de apresentar uma imagem utêntica de si mesmo. Por isso, eles não tratam do ser humano 'real', cuja proximidade com ao cotidiano deveria he confiar autenticidade, nem de uma presentação 'verdadeiro' de um suposto Eu por parte dos performer, mas de um jogo estratégias de (auto-)apresentação

Um desdobramento parecido pode ser oservado também nas mídias de massa. Nos formatos da televisão encontra-se um crescente número de 'representadores' que não são mais introduzidos como atores ou apresentadores profissionais - começando deBig Brother (2000), passando pelos Reality 
Soaps até Deutschland sucht den Superstar Alemanha procura o superstar; um show de talentos musicais] (2003). Enquanto, no início, um dos objetivos desses formatos era, através da criação de configurações de teste extremas - seja de uma isolação do mundo afora, ou através de provocações desafios - fazer com que os candidato se apresentem de modo autêntico, agor esta busca por autenticidade aparece em segundo plano. Os formatos mais novo observam os candidatos no processo de se tornar auto-apresentadores mais mais aperfeiçoados, por exemplo, quando eles aperfeiçoam a sua auto-encenação enquanto popstars. $\mathrm{O}$ espectador não mai pontua como os candidatos são além da câmara, mas como eles constroem um imagem em frente e para a câmara que parece autentico. O objetivo não parece se a confecção de autenticidade para além da encenação, mas a autenticidade no ato d encenação.

Na descrição das formas teatrais de representação - tanto no contexto dos 'atores' não-profissionais quanto no teatroperformance - chama a atenção também que se recorre com tanta freqüência ao conceito de autenticidade, e simultaneamente questiona. ${ }^{6}$ Mesmo que se questione a autenticidade do apresentado e o conceito seja definido de modo problemático, ele continua sendo o ponto de referência d descrição. Deste modo, o conceito sempre marca também a dúvida acerca do autêntico e se define em última análise através do seu oposto: o fingimento ou a falsificação.

Esta atitude cética acerca do conceito de autenticidade encontra-se em discursos uma comunicação não-mediata e direta. As teorias do gênero indagam com concepções como performatividadee máscara a autenticidad do gênero. A teoria literária se despede da instância do autor recorrendo a conceitos

Ver, por exemplo, Diez, Georg. "Das Drama des wirklichen Le Juni 2005; Bauer, Detlev. "Echt gespielt" "representado de ver-

7 Römer, Stefan: Künstlerische Strategien des Fake. Kritik von
Original und Fälschung, Köln: DuMont, 2001. como a intertextualidade. E a etnologia problematiza qualquer forma de uma documentação autêntica. Frente a este contexto, Helmut Lethen questiona a autenticidade como critério de avaliação: "Quando não é mais possível denomina interfaces claras entre natureza e construção social, a autenticidade parece ser usada no máximo de forma irônica para diferenciar entre vários graus de artificialidade."

Esta interface entre vários graus de artificialidade, no entanto, é típico para a discussão contemporânea sobre autenticidade e encenação no palco. Investigar e buscar a imediatez com os meios do palco é uma tentativa um tanto paradoxal: O contexto 'palco' aponta exatamente para o caráter mediado do apresentado. Autenticidade no palco é sempre efeito de uma construção. Gabriele Brandstetter vê neste fato um novo paradoxo do ator, na sucessão de Diderot, um "estar presente sem atuar" ${ }^{10}$ O paradoxo não se articula mais entre sentimento e representação, mas entre desejo por uma representação autêntica e o saber simultâneo da sua impossibilidade. Com isso, a autenticidade se transforma de um problema da representaçãocomo posso conseguir uma representação autêntica? - em um problema da retórica: como posso comunicar ao espectado a impressão de imediatez no palco, se qualquer impressão de autenticidade esultado de uma construção?

Um breve excursão pela história da atuação documenta o deslocamento de conceito de autenticidade em relação a esta

${ }^{8}$ Lethen, Helmut. "Versionen des Authentischen. Sechs Gemeinmut e Scherpe, Klaus (eds.) Literatur und Kulturwissenschatftent Positionen, Theorien, Modelle. Reinbek bei Hamburg: Rowoh
1996., p.205-230, aqui p 20.

Ver Fischer-Lichte, Erika e Pflug, Isabel (eds). Inszenierung
von Authentizität IEncenacōos de autenticidade]. Tübingen asel: Francke, 2000. E também Berg, Jan; Hügel, Hans-Otto; Kurzenberger, Hajo. (eds.) Authentiziziät als Darstellung [AuHildesheim, 1997.

${ }^{10}$ Brandstetter, Gabriele. "Geschichten erzählen im Performan-
ce-Theater der neunziger Jahre." In: Fischer-Lichte, Erika et. al. (eds). Transformationen: Theater der 90ger Jahre [Transform pergunta. Nas teorias de atuação do século 18 , se buscou por autenticidade tanto na expressão do ator quanto na representação do personagem. Esta exigência focou uma determinada concepção de uma representação 'natural', em oposição a uma representação artificial e exagerada. ${ }^{11}$ A partir da metade do século XIX, as exigências ao ator mudam: Ele deve sempre, na representação da figura, também representar ele mesmo. ${ }^{12}$ Nas teorias do teatro no início do século $X X$, a relação entre palco e realidade é invertida: não o teatro, mas a realidade social é marcada pelo fingimento. Stanislavski, por exemplo, compreende a sua técnica de atuação como uma tentativa "de como podemo apreender de eliminar do teatro [...] teatral'."13 Principalmente a concepção de Grotowski do seu Teatro Pobre define o ato de atuação como instrumento para atingi uma veracidade. $O$ ator, através do trabalho sobre ele mesmo e sobre o personagem deve alcançar uma veracidade impossíve na vida cotidiana. O palco é declarado com o lugar em que esta forma de autenticidade parece possível.

Os trabalhos contemporâneos, ao contrário, revelam auto-encenações que conscientemente não escondem $\mathrm{o}$ seu caráter de serem um jogo construído. As apresentações investigam as encenações do cotidiano e suas estratégias de atribuir-lhes autenticidade. A auto-representação se apresenta como um jogo com identidades, como um modo de representação, na sua multiplicação em imagens mais diversas de si mesmo. Neste contexto, questão do verdadeiro, da veracidade e da credibilidade se torna inane. Isto faz com que a percepção do espectador vira o elemento central: não se coloca mais a

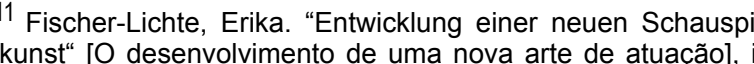

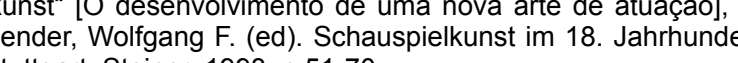
tuttgart: Steiner, 1998, p.51-70.

Emblemático para este fenômeno é o debate sobre a difer heatergöttinnen. Inszenierte Weiblichkeit. Clara Ziegler, Sara Bemhard, Eleonore Duse. FrankfurtMain. Stroemifeld, 1994.

${ }^{13}$ Stanislavski, Konstantin. Die Arbeit des Schauspielers na sich
selbst: Tagebuch eines Schülers. [0 trabahlho do ator sobre si
mesmo: diário de um aluno]. Vol.1, Berlin:Henschel, 1983. questão se algo é imediato ou encenado, mas que impressão de imediatez produzida. Se expõe a construção de feitos do autêntico. Neste processo, podese diferenciar várias estratégias.

Um procedimento consiste em desvendar a construção do acontecimento teatral propriamente dito. Podemos mostrar isso de forma exemplar na encenação STANDBILD MIT RANDEXISTENZEN, descrita no início deste artigo. Ao permiti um conhecimento sobre a seleção dos 'atores' e sobre os parâmetros expostos na encenação, a apresentação revela ua estrutura. Esta exposição e revelação funcionam, no entanto, somente perante o contexto 'teatro' e das suas convenções inscritas neste. $\mathrm{O}$ que se percebe como autentico é o gesto do desvendamento. modo da 'encenação' é afirmado como realidade comum entre espectadore e 'atores'. Esta concepção de realidade não refere a algo extra-teatral, mas a um determinado clima de comunicação: o que mporta é uma definição compartilhada da situação como sendo encenada. Este procedimento se diferencia da conceito Brechtiano do distanciamento na medida em que não há uma ilusão teatral na situação da apresentação que poderia ser quebrada, do mesmo modo como não há figuras fictícias ou uma fábula. Aquilo que se expõe enquanto encenação é meramente a situação teatral de representar e observar. ostas camadas da encenação, cria-se a impressão de autenticidade só a partir da diferença. Quanto menos encenado, mais autêntico o efeito em omparação com algo mais encenado.

Um outro procedimento é recorrer conhecidos formatos da mídia, ou cultural performances, nos quais são inscrito específicas estratégias de encenação reconhecíveis pelos espectadores. O grupo Rimini Protokoll, por exemplo, faz uso uma e outra vez, de formas de encenação ociais para as suas produções, seja isso parlamento alemão em DEUTSCHLAND 2, ou a sala de um tribunal em Zeugen [testemunhas]. Se examina a produção e 
recepção de procedimentos e estratégias de encenação na política e no sistema jurídico respectivamente. Neste contexto, levantase a questão como se produz 'a verdade' nessas formas sociais de encenação, e quai 'papeis' são assumidos. Procedimento de encenação teatrais se misturam com aqueles da realidade social. Os 'atores' nãoprofissionais legitimam o seu aparecimento no palco com o fato de serem expertos par uma forma específica de encenar realidade empírica - seja por causa de uma predileção pessoal, da sua profissão ou de uma determinada experiência biográfica. Ele causam uma impressão de autenticidade enquanto expertos, não enquanto 'atores' teatrais. Mas a sua competência, por sua vez, é exposta como uma forma específica de (auto-) encenação. Na oposição das diferentes estratégias de encenação surge impressão de autenticidade como efeito de diferenças

Isso aponta para um terceiro efeito de autenticidade no palco: o fracasso da (auto-) encenação bem fabricada. No teatro tradicional, relaciona-se um momento de autenticidade com o fracasso do andamento fluído da apresentação: um ator 'sai do personagem', a técnica não funciona ou alguém se machuca. A "irrupção do real" causa a impressão de autenticidade dentro da situaçãoencenada. Em muitas produções contemporâneas, este fracasso é parte $\mathrm{d}$ encenação. Por um lado, ele é produzido por uma falta de profissionalismo dos 'atores', que muitas vezes aparecem pela primeira vez num palco. Os 'atores' não-profissionais freqüentemente não conseguem produzir aspectos rotineiros de atuação - por exemplo uma sensibilidade em relação ao texto, uma voz audível ou um sensibilidade específica pela linguagem pelo corpo. Na sua atuação, eles minam as convenções da representação no palco. Por causa desta falta de profissionalismo, criase uma cumplicidade com o público: por mais que sejam especialistas na sua própria profissão, eles são ao mesmo tempo não- especialistas enquanto atores. Podemos constatar um diletantismo da forma. Deste modo, a encenação se transforma em um arranjo experimental que brinca de modo consciente com o fracasso na representação: a atenção se desloca da capacidade artístico-representacional dos atores para suas capacidades de autoencenação. O centro da questão agora é como eles se apresentam e tratam a situação da encenação. A impressão de autenticidade surge pelo modo de minar o que é esperado, pelo erro da encenação

Algo parecido acontece quando grupos erformáticos como Forced Entertainment Gob Squad ou SheShePop trabalham com estruturas de jogo no palco, que exigem do performer a capacidade de improvisação no palco. A montagem QUIZOOLA! do grupo Forced Entertainment, por exemplo, é um jogo de perguntas e respostas que trabalha com a característica de que a situação do jogo é aberta. Dois performers se enfrentam sentados e cara a cara no palco. De um bolo de mais do que mil perguntas, eles fazem perguntas um ao outro. As respostas são improvisadas por ambos. O espectado pode perceber as regras que organizam a apresentação. No contexto do teatro se estabelece um segundo frame do jogo que coloca o performer numa situação de decisão concreta. A duração da montagem, entre quatro a seis horas, faz parte da estratégia de autenticação. Durante este tempo longo, os performers passam necessariamente por dificuldades deconcentração. Elescomeçam a rir, param no meio da fala, começam a gaguejar, fazem pausas longas para refletir (desesperadamente). Cria-se um momento de sobrecarrego que desencadeia afetos visíveis nos performers: vergonha e embaraço. A vergonha, que se caracteriza pelo desejo de "não estar aqui agora", torna a presença inevitável dos 'atores' algo obsessivo. Ela não se deixa integrar (aparentemente) na auto-encenação, e os 'atores' perdem o controle sobre a situação teatral. O tempo de duração parece assim um truque consciente para consegui uma perda de controle e, com isso, uma imediatez: uma tentativa de produzir afetos reais através de determinados efeitos. Ao mesmo tempo, este truque faz parte da configuração da situação, transparente para o espectador. $\mathrm{O}$ fracasso é e sempre será parte da encenação.

Neste contexto, os dois pólos 'autêntico' 'encenado' referem um ao outro. autêntico é encenado desdejá, e a encenação responde a um fracasso autêntico. Este jogo ambíguo aponta para um conceito d uma 'autenticidade irônica': autenticidade é afirmada, mas não é aquilo que se quer dizer. É justamente a diferença entre mostrado e o não-afirmado que possibilita: algo com intenções sérias, uma afirmação irônica, uma transgressão autêntica de algo necessariamente mediado, representação da impossibilidade dessa transgressão.

No entanto, resta a pergunta, porque autenticidade continua sendo um ponto de referência na descrição de representações teatrais. Se a brincadeira com os efeitos de autenticidade é mais do que um mero meio para um fim, deste tratamento de autenticidade, irônico e abertamente encenado, resultam novas reivindicações e esperanças, como Christoph Schlingensief as define: "O meu desejo é grande de encontrar um sistema que é satisfeito consigo mesmo, mas do qual os participantes sabem que é um sistema enganoso. Ao afirmar que algo é teatro, ao apresentar algo e confessar seu caráter como fake, se cria uma nova sinceridade."15 Aqui surge uma outra compreensão de autenticidade. Junto à exposição de 'atores' não-profissionais, ao desvendamento dos parâmetros da encenação, à brincadeira com o risco do fracasso, é a própria constituição do acontecimento teatral que vira foco. Todos que vão ao teatro sabem do status do apresentado. $\mathrm{O}$ evento teatral

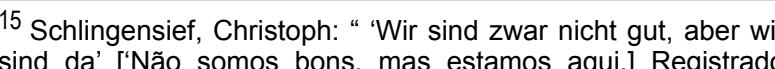
epois de uma conversa lia Lochte e Wilfried Schulz." In: Julia Lochte e Wilfried Schulz
(eds). Schlingensief. Notruf für Deutschland; über die Mission, (eds). Schlingensilef. Notrut fur Deutschland; über die Mission
das Theater und die Welt des Christoph Schlingensief. Hamburg Rotbuch, 1998. p. 12-35, aqui p.35.

SERES HUMANOS REAIS E PERFORMERS VERDADEIROS não funciona através o engano ou o equivoco entre realidade e ficção. Ao contrário: a realidade teatral se destaca pelo conhecimento compartilhado das condições do apresentado, pela possibilidade de reconhecer o ato de mostrar, e pela tentativa produtiva compartilhada de estabelecer uma comunicação sobre este ato. Neste ponto reside o potencial do teatro no contexto de uma discussão das formas de encenação presentes na nossa sociedade, numa época em que a impossibilidade de distinguir entre o real e o encenado está e tornando um problema (do cotidiano) Não se trata mais se algo é real ou verdadeiro, mas de uma diferenciação entre os diferentes graus de encenação não do desmascaramento da realidade social como encenada, mas de uma entativa de responder com os meios do palco e em igual grau de complexidade à complexidade social. 


\section{REFERÊNCIAS BIBLIOGRÁFICAS}

BALK, Claudia. Theatergöttinnen. Inszenierte Weiblichkeit. [Deusas do Teatro. Feminilidade encenada] Clara Ziegler, Sarah Bernhardt, Eleonore Duse. Frankfurt/Main: Stroemfeld, 1994

BAUER, Detlev. "Echt gespielt" [representado de verdade], in: Deutsche Bühne 8 (2004)

BEHREND, Eva. "Die Alltagsspezialisten", in Jahrbuch Theater heute (2003)

Berg, Jan; HüGel, Hans-Otto; e Kurzenberger, Hajo. (eds.) Authentizität als Darstellung [Autenticidade enquanto representação]. Hildesheim: Universität Hildesheim, 1997

BRANDSTEtTER, Gabriele. "Geschichten erzählen im Performance-Theater der neunziger Jahre." In: Fischer-Lichte, Erika et. al. (eds). Transformationen: Theater der 90ger Jahre [Transformações: teatro dos anos 90]. Berlin: Theater der Zeit, 1999

DiEZ, Georg. "Das Drama des wirklichen Lebens" [o drama da vida real], in Frankfurter Allgemeine Zeitung, 5. Juni 2005.

Fischer-Lichte, Erika e Pflug, Isabel (eds). Inszenierung von Authentizität [Encenações de autenticidade]. Tübingen e Basel: Francke, 2000

Fischer-Lichte, Erika. "Entwicklung einer neuen Schauspielkunst" [O desenvolvimento de uma nova arte de atuação], in: BENDER, Wolfgang F. (ed). Schauspielkunst im 18. Jahrhundert. Stuttgart: Steiner, 1998

LeHmann, Hans-Thies. Teatro pós-dramático. São Paulo: Cosac\&Naïfy, 2007

LETHEN, Helmut. "Versionen des Authentischen. Sechs Gemeinplätze“ [Versões do autêntico: seis chavões], in: BÖHME, Hartmut e SCHERPE, Klaus (eds.) Literatur und Kulturwissenschaften: Positionen, Theorien, Modelle. Reinbek bei Hamburg: Rowohl, 1996

RÖMER, Stefan: Künstlerische Strategien des Fake. Kritik von Original und Fälschung. [Estratégias artísticas do fake. Crítica de original e falsificação]. Köln: DuMont, 2001. 